\title{
Electrophysiological basis for the use of adenosine in the diagnosis and treatment of cardiac arrhythmias
}

The nucleoside adenosine has increasingly been recognised to be useful in the treatment and diagnosis of cardiac arrhythmias..$^{1-5}$ The most recent articles of Rankin et al ${ }^{6}$ and Till $e t a l^{7}$ confirm this and provide further evidence of the usefulness and applicability of giving intravenous boluses of adenosine as a therapeutic and diagnostic tool in the short term management of supraventricular arrhythmias.

An understanding of the cellular electrophysiological effects of adenosine was vital in the development of the clinical use of this nucleoside. ${ }^{8}$ The potential for developing additional clinical uses for adenosine or related compounds (that is agonists and antagonists) rests on further delineation of the cellular and molecular mechanisms of their action.

Our object is to describe the current knowledge of the cellular electrophysiological actions of adenosine and to provide well established examples in which such knowledge has led to the successful use of this nucleoside in the management of cardiac arrhythmias.

\section{Basis of action of adenosine}

Adenosine is an endogenous nucleoside whose production is increased in response to stimuli such as hypoxia and ischaemia. ${ }^{8}$ In addition to its coronary vasodilatory properties, adenosine has considerable electrophysiological effects on the specialised tissues of the heart-that is the sinoatrial and atrioventricular nodes and working myocardium. ${ }^{8}$ Adenosine induced depression of the pacemaker activity of the sinoatrial node and of atrioventricular nodal transmission is responsible for the negative chronotropic (bradycardia) and dromotropic (atrioventricular block) effects caused by the nucleoside. Thus adenosine regulates atrial and ventricular rates independently of each other. In addition to these effects on the specialised tissues, adenosine produces a concentration-dependent shortening of the action potential and hyperpolarisation in the atrial myocardium-effects that are accompanied by a negative inotropic response. ${ }^{8}$ On the other hand, in the absence of catecholamine stimulation, adenosine causes no discernible electrophysiological or inotropic effect in ventricular myocardium. ${ }^{89}$ So adenosine has no effect unless the adenylyl cyclase-cAMP system is first stimulated. However, under conditions of enhanced adenylyl cyclase activity (that is raised concentrations of cAMP), the electrophysiological (including triggered activity) and positive inotropic effects of $\beta$ adrenergic stimulation are antagonised by adenosine. ${ }^{89}$

The cellular basis for adenosine's effects in supraventricular tissues is mainly the activation of a specific potassium-outward current $\left(\mathrm{I}_{\mathrm{KACh}, \mathrm{Ado}}\right)$-that is the so-called acetylcholine regulated potassium channels. ${ }^{1011}$ Other mechanisms of action of adenosine include inhibition of the catecholamine stimulated calcium inward current $\left(\mathrm{I}_{\mathrm{Ca}}\right)$ and in sinoatrial node cells attenuation of the pacemaker current $\left(I_{F}\right)$ stimulated by isoprenaline. ${ }^{12}{ }^{13}$ In contrast, the figure shows that the acetylcholine regulated potassium channels are not present in ventricular myocytes; the electrophysiological actions of adenosine in these cells are mainly caused by the attenuation of catecholamine stimulated $\mathrm{I}_{\mathrm{Ca}}$ and catecholamine induced transient inward currents $\left(I_{T_{\mathrm{T}}}\right)$, which is responsible for the delayed afterpotentials that often lead to trigger activity. ${ }^{14}{ }^{15}$ Pacemaker activity arising from Purkinje fibres, stimulated by catecholamines, can also be depressed by adenosine. ${ }^{16}$

\section{Clinical actions of adenosine}

These electrophysiological properties of adenosine, for the most part, form the basis for its clinical antiarrhythmic actions. Adenosine has proved to be effective ( $>90 \%$ ) in terminating supraventricular tachycardia in which the atrioventricular node forms one of the limbs of the reentrant circuit, such as atrioventricular reciprocating tachycardia and atrioventricular nodal reentry. ${ }^{1}$ By transiently interrupting impulse propagation through the atrioventricular node, adenosine effectively terminates these types of supraventricular arrhythmias. Some accessory pathways with decremental conduction properties have also been shown to be sensitive to adenosine, ${ }^{17}$ which could explain the adenosine induced termination of long $\mathbf{R P}^{\prime}$ tachycardia in the retrograde limb of the reentrant circuit reported by Till et al. ${ }^{7}$ Transient atrioventricular block caused by adenosine has also been shown to be useful in unmasking atrial rhythms (for example, atrial tachycardia and flutter) that are otherwise concealed by the ventricular depolarisations. ${ }^{14}$ In addition, in atrial tissue, hyperpolarisation (caused by an increase in $\mathrm{I}_{\mathrm{KACh}, \mathrm{Ado}}$ ) caused by adenosine may stabilise membrane potentialthat is, decrease excitability. ${ }^{10}$ Whether this potential effect is responsible for the termination of focal atrial tachycardias such as those reported by Perelman and Krikler ${ }^{18}$ remains to be established.
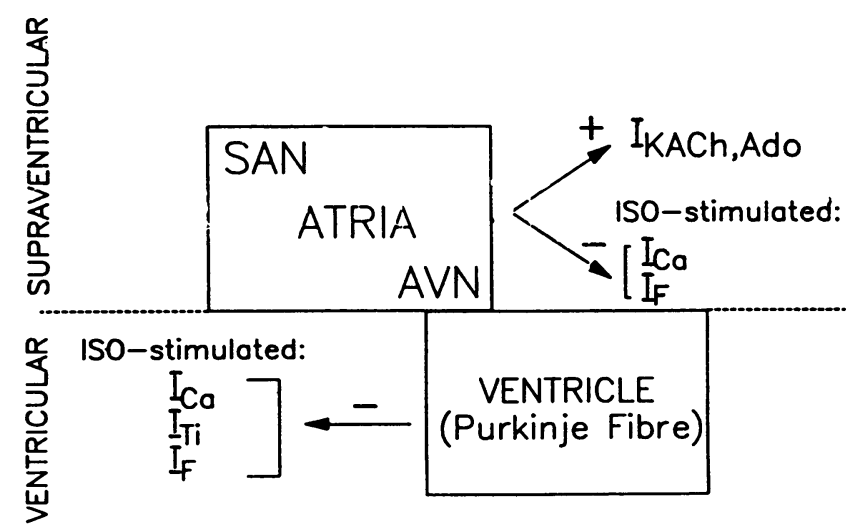

Figure Effect of adenosine on ionic currents of cardiomyocytes. Activation of cardiac adenosine $A_{1}$ receptor produces several electrophysiological signals. In supraventricular tissue, including electrophysiological signals. In supraventricular tissue, including
sinoatrial $(S A)$ and atrioventricular $(A V)$ nodes $(N)$, adenosine activates a potassium outward current $\left(I_{K A C h, A d o}\right)$ and antagonises the catecholamine stimulation of calcium inward current $\left(I_{C_{a}}\right)$ and pacemaker current $\left(I_{F}\right)$. In the ventricular myocardium adenosine only antagonises the effects of catecholamines such as isoproterenol (ISO)stimulated $I_{C a}, I_{F}$, and ISO-induced transient inward current $\left(I_{T i}\right)$. 
Also of importance and consistent with its ability to abolish catecholamine-facilitated triggered activity in isolated ventricular myocytes, adenosine has been shown to terminate episodes of ventricular tachycardia in a distinct subset of patients-those with exertion-related sustained ventricular tachycardia and normal hearts. ${ }^{5}$ This effect of adenosine seems to be specific for this mechanism of ventricular tachycardia because so far it has been ineffective in ventricular tachycardias thought to be caused by reentry or enhanced automaticity. ${ }^{5}$ This important action of adenosine combined with its rather specific effect on the atrioventricular node provides very useful diagnostic information for wide-complex tachycardia as clearly shown in recent studies. ${ }^{46}$

A major clinical advantage of adenosine is that its side effects are transitory (seconds) and relatively benign, because of its rapid cellular metabolism. Side effects predominantly include flushing, dyspnoea, and chest pain. Atrioventricular block may also occur, but is seldom symptomatic. Rankin et $a l^{6}$ reported considerably more mild $(63 \%)$ and severe $(36 \%)$ side effects with injections of adenosine boluses than did earlier studies, including a recent trial in the United States of 358 patients. ${ }^{12}{ }^{19}$ In the earlier studies, the overall incidence of mild side effects was approximately $20-29 \%$ and severe side effects $<0.5 \%$; all were transient and did not require treatment. ${ }^{1219} \mathrm{~A}$ possible explanation of the discrepancy in the incidence of side effects is that in the study of Rankin et $a l^{7}$ the doses of adenosine used were as high as 20 to $25 \mathrm{mg}$, whereas in the trial in the-United States ${ }^{19}$ the maximum dose was $12 \mathrm{mg}$. Nevertheless, the fact that adenosine has been shown to terminate paroxysmal supraventricular tachycardia without complications in haemodynamically compromised children is consistent with adenosine's high degree of safety. ${ }^{37}$

\section{Conclusion}

There are still many potential electrophysiological mechanisms that can account for the antiarrhythmic properties of adenosine; however, further investigation is needed to ascertain not only which of the mechanisms are clinically relevant, but also the pathophysiological role of adenosine in the genesis of disturbances of cardiac rhythm. ${ }^{2021}$ Therefore, the development of selective adenosine related compounds (that is agonists and antagonists) and other modulators may become a fruitful area of investigation that could lead to other approaches to the treatment and diagnosis of cardiac arrhythmias.

LUIZ BELARDINELLI

Departments of Medicine and Pharmacology,

University of Florida,

Gainsville

Florida, USA

Division of Cardiology

Department of Medicine

The New York Hospital,

Cornell Medical Centre,

New York, USA
The original work described in this review was supported by grants from the National Institutes of Health and the American Heart Association/Florida Affiliate and Suncoast Chapter. B B L is the recipient of an Established Investigatorship Award from the American Heart Association. His present address is The New York Hospital-Cornell Medical Center, Division of Cardiology, 525 East 68th Street, Starr 4, New York, NY 10021, USA.

Correspondence to Dr Luiz Belardinelli, Department of Medicine, Box J-277 JHMHC, University of Florida, Gainesville, Florida 32610, USA

DiMarco J, Seller DT, Lerman BB, Greenberg ML, Berne RM, Belardinelli L. Diagnostic and therapeutic use of adenosine in patients with supraventricular tachyarrhythmias. J Am Coll Cardiol 1985;6:417-25.

2 Munoz A, Leenhardt A, Sassine A. Therapeutic use of adenosine for terminating spontaneous paroxysmal supraventricular tachycardia. Eur Heart $J$ 1984;5:735-8.

3 Clarke B, Rowland E, Barnes PJ, Till J, Ward DE, Shinebourne RA. Rapid and safe termination of supraventricular tachycardia in children by adenosine. Lancet 1987;i:299-301.

4 Griffith MJ, Ward DE, Linker NJ, Camm AJ. Adenosine in the diagnosis of broad complex tachycardia. Lancet 1988; i:672-6.

5 Lerman BB, Belardinelli L, West GA, Berne RM, DiMarco JP. Adenosinesensitive ventricular tachycardia: evidence suggesting cyclic AMPsensitive ventricular tachycardia: evidence suggesting
mediated triggered activity. Circulation 1986;74:270-80

6 Rankin AC, Oldroyd KG, Chong E, Rae AP, Cobb SM. Value and limitations of adenosine in the diagnosis and treatment of narrow and broad complex tachycardias. Br Heart J 1989;62:195-203.

7 Till J, Shinebourne EA, Rigby ML, Clarke B, Ward DE, Rowland E. Efficacy and safety of adenosine in the treatment of supraventricular tachycardia in infants and children. Br Heart $J 1989 ; 62: 204-11$.

8 Belardinelli L, Linden J, Berne RM. The cardiac effects of adenosine. Prog Cardiovasc Dis 1987;32:73-97.

9 Belardinelli L, Isenberg G. Actions of adenosine and isoproterenol on isolated mammalian ventricular myocytes. Circ Res 1983;53:287-97.

10 Belardinelli L, Isenberg G. Isolated atrial myocytes: adenosine and acetylcholine increase potassium conductance. Am J Physiol 1983;244:H734-7.

11 Kurachi $Y$, Nakajima T, Sugimoto T. On the mechanism of activation of muscarinic $\mathrm{K}^{+}$channels by adenosine in isolated atrial cells: involvement of GTP-binding proteins. Pflügers Arch 1986;407:264-74.

12 Cerbai E, Klöckner U, Isenberg G. Ca-antagonistic effects of adenosine in guinea pig atrial cells. Am J Physiol 1988;255:H872-8.

13 Belardinelli $L$, Giles $W$, West $A$. Ionic mechanism of adenosine actions in pacemaker cells from rabbit heart. J Physiol (Lond) 1988;405:615-33.

14 Isenberg $G$, Belardinelli $L$. Ionic basis for the antagonism between adenosine and isoproterenol on isolated mammalian ventricular myocytes. Circ Res and isoproteren

15 Belardinelli L, Wu S-N, Visentin S. Adenosine regulation of cardiac electrical activity. In: Zipes DP, Jalife J, eds. Cardiac electrophysiology, from cell to bedside. Philadelphia:WB Saunders, 1989: chapter 32 (part V), 344-53.

16 Rosen MR, Danilo P, Weiss RM. Actions of adenosine on normal and abnormal impulse initiation in canine ventricle. Am J Physiol 1983;244:H715-21

17 Lerman BB, Greenberg M, Overholt ED, et al. Differential electrophysiologic properties of decremental retrograde pathways in long $\mathbf{R P}^{\prime}$ tachycardia. Circulation 1987;76:21-31.

18 Perelman MS, Krikler DM. Termination of focal atrial tachycardia by adenosine triphosphate. Br Heart $J$ 1987;58:528-30

19 Adenosine Study Group. Adenosine for termination of paroxysmal supraventricular tachycardia: dose ranging and comparison with verapamil [Abstract]. Circulation 1989;80:II-631.

20 Wesley RC, Lerman BB, DiMarco JP, et al. Mechanism of atropine-resistant atrioventricular block during inferior myocardial infarction: possible role of adenosine. J Am Coll Cardiol 1986;8:1232-4.

21 Shah PK, Nalos P, Peter T. Artropine resistant post-infarction complete AV block: possible role of adenosine and improvement with aminophylline. Am Heart J 1987;113:194-5. 